Ergo

\title{
A New Puzzle for Phenomenal INTENTIONALITY
}

\author{
PETER CLUTTON \\ Australian National University \\ ALEXANDER SANDGREN \\ Umeå University
}

\begin{abstract}
Phenomenal intentionality theories have recently enjoyed significant attention. According to these theories, the intentionality of a mental representation (what it is about) crucially depends on its phenomenal features. We present a new puzzle for these theories, involving a phenomenon called 'intentional identity', or 'cointentionality'. Co-intentionality is a ubiquitous intentional phenomenon that involves tracking things even when there is no concrete thing being tracked. We suggest that phenomenal intentionality theories need to either develop new uniquely phenomenal resources for handling the puzzle, or restrict their explanatory ambitions.
\end{abstract}

Keywords: Intentionality; intentional identity; hooded man paradox; phenomenal intentionality.

\section{Introduction}

Some mental states exhibit intentionality: they are of, about, or directed at things. On seeing my flat tire early on a Monday morning, my perception is directed at my flat tire; my memory of getting the flat tire is a memory of the time my tire was punctured; and my belief that I now have a flat spare is about the flat spare. An account of intentionality aims to explain how mental states have this kind of intentionality. According to phenomenal intentionality theories (PITs), which have recently enjoyed significant attention (Bailey \& Richards 2014; Bordini 2017;

Contact: Peter Clutton <peter.clutton@anu.edu.au> and Alexander Sandgren <alexander. sandgren@umu.se> 
Forrest 2017; Goff 2017; Horgan 2013; Kriegel 2013; Mendelovici 2018; Montague 2016), the intentionality of mental states has its basis in their phenomenology.

There is a familiar challenge to PITs based on the initially plausible claim that what a mental representation is about sometimes depends on facts that do not supervene on the representer's narrowly construed psychological state. Since the phenomenology of a mental representation plausibly depends on the representer's narrowly construed psychological state, this looks like a problem for PITs. There are, broadly speaking, two established kinds of responses to this challenge. We will spell out the challenge and outline the most common responses below.

Our goal in this paper is to present a novel kind of challenge for PITs centered on the relation of being about the same thing that stands between some mental representations. This relation is often called 'intentional identity' (though we prefer the term 'co-intentionality'). The new challenge makes some of the established responses to the familiar challenge look less attractive, and raises interesting issues of its own. The new puzzle might suggest to some that PITs need to be revised; it might suggest to others that PITs should be rejected. All we wish to do in this paper is present the new puzzle, relate it to the familiar puzzle and the most common responses to it, and draw out some lessons from the new puzzle. In doing so, we explore the best options for PITs for dealing with this new puzzle. We encourage others to build on this foundation.

\section{Phenomenal Intentionality Theories}

According to phenomenal intentionality theories, the intentionality of mental states has its basis in their phenomenology. In a slogan: the 'what it is aboutness' of a mental state is tied to its 'what it is likeness'.

PITs differ in detail. One difference involves the nature of the relationship between intentionality and phenomenology. A common view is that it is a grounding relation (Farkas 2008), wherein the phenomenology grounds intentionality. The claim that the relationship is one of identity has also been defended (Mendelovici 2018).

Another key difference involves what PITs say about purportedly nonphenomenal instances of intentionality. Some mental states, like beliefs and other 'standing' states, appear to be dispositional and non-phenomenal; others, like some of the sub-personal states posited by cognitive science, appear to be occurrent but unconscious. Some proponents of PITs deny that these kinds of mental states are intentional at all (or that at most, talk of dispositions as intentional is a mere 'façon de parler') (Strawson 2005: 45). Others grant them intentionality of a sort, perhaps of a derivative or interpreted variety (for some review, see Kriegel 
2003; 2011). Still others grant them genuine intentionality, as long as (and in virtue of the fact that) they have the proper links to occurrent phenomenal states, or that they inhere in experiencing beings (Searle 1992; Strawson 2009).

For the present purposes, these and other details can be glossed over. What these accounts share is a commitment to a unique role for phenomenology in determining the intentionality of at least some mental states. This is supposed to set these theories apart from views - often termed 'naturalistic accounts' of intentionality - that tend to distinguish the phenomenal and intentional. ${ }^{1}$ It also sets them apart from views such as representationalism, according to which the explanatory order is reversed-intentionality determines or constitutes phenomenology. ${ }^{2}$

Our target, then, will be phenomenal intentionality theories broadly construed. We will consider all PITs that claim that a crucial part of a mental representation's intentionality supervenes on its phenomenology. Some PITs make stronger claims, but this weaker thesis will be enough for us to present our puzzle. Where necessary, we will frame our examples in terms of occurrent conscious mental states, to avoid the controversy that surrounds states like standing propositional attitudes.

\section{A Familiar Puzzle}

\subsection{The Hooded Man}

Consider the following cases: ${ }^{3}$

Brother: You see a hooded man drinking at the third seat at the bar. You do not recognise the man drinking at the third seat at the bar. You judge that the man seated at the third seat at the bar is tall. The man drinking at the third seat at the bar is in fact your brother.

1. What are termed 'naturalistic' accounts of intentionality tend to be separatist about phenomenology and intentionality, though these are distinct concepts.

2. Though one could argue that the distinction breaks down on certain formulations, particularly if the posited relation between phenomenology and intentionality is one of identity.

3. The hooded man puzzle originates from a set of paradoxes originally presented by Eubilides, who formulate it as follows Priest (2002: 445): 'You say you know your brother. But that man who came in just now with his head covered is your brother, and you do not know him.' We avoid formulating the puzzle in terms of attitude ascriptions, since we are interested in intentional attitudes themselves, not how those attitudes are signaled in language (an interest shared by proponents of PITs). 
Stranger: You see a hooded man drinking at the third seat at the bar. You do not recognise the man drinking at the third seat at the bar. You judge that the man seated at the third seat at the bar is tall. The man drinking at the third seat at the bar is in fact a stranger to you.

It appears as if in the brother case your occurrent judgment is about your brother, while in the stranger case it is not. Your judgment appears to be about different things in the two cases and this is, it seems, an intentional difference between the cases; your judgment 'that hooded man at the bar is tall' is about your brother in the brother case, but not so in stranger case. ${ }^{4}$

However, the phenomenology of your experience appears to be the same in the two cases. ${ }^{5}$ The man drinking at the third seat at the bar is, in some sense, presented as a stranger-from your perspective-in both cases. Your narrowly construed psychology (which plausibly captures any relevant phenomenology) appears to be the same in the two cases. But this would imply that the intentional properties of the representations (what they are about) do not always depend on their phenomenology, since there is an intentional difference between the brother and stranger cases but no difference in the relevant phenomenology.

Proponents of PITs seem to agree that they owe an explanation of what is going on in cases like these (see, e.g., Mendelovici \& Bourget 2014; 2017). That is, in order for the theory to remain plausible, 'it has to provide a satisfactory treatment of the kinds of states that we might pre-theoretically consider to be intentional' (Mendelovici \& Bourget 2014: 331). When confronted with some such seemingly intentional phenomenon, PIT must either show that it can be explained in terms of phenomenal intentionality (either directly or derivatively), or argue that the phenomenon is not in fact intentional after all. How do proponents of PIT respond to the hooded man puzzle?

\subsection{The Options}

The first kind of response is to insist that the puzzle really can be adequately accounted for in terms of phenomenal intentionality. We might call this holding true. Those who hold true stick to their phenomenal-intentional guns. They claim that contrary to appearances, there is a phenomenal (and intentional) difference between the brother and stranger cases that is tied to the difference in which object is in fact presented to you. The idea is that which object the mental

4. It is a common claim of PITs that there is phenomenal intentionality of thoughts such as judgments; we grant this claim for the sake of argument.

5. This tension is similar to that standardly brought out with twin earth cases and the like; we hope to avoid some of the extra baggage (involving linguistic communities, natural kinds, and so on) that comes along with twin earth cases. 
representation is about makes a difference to the phenomenology of that representation. This view is sometimes discussed in relation to Martin (2002a; 2002b), by way of Evans (1982) and McDowell (1986). ${ }^{6}$

The other kind of response is to make some kind of exclusion, either regarding the reach of phenomenology or on what sorts of phenomena PITs are supposed to explain. Both kinds of exclusions begin with a distinction between the narrow features of mental representations (which depend on facts about the agent's psychological state) and wide features of mental representations (which depend partly on facts external to the agent's psychology). ${ }^{7}$

One way of making an exclusion is to say that the intentional difference between the brother and the stranger cases involves the wide features of the representations, and that this wide kind of intentionality is outside the scope of PITs. Phenomenal intentionality theories concern the narrow features of mental representations, not the wide. Call this the phenomenal exclusion. According to those who make this move there really is an intentional difference between the cases and no phenomenal difference, but this is not so puzzling after all, given the narrow-wide distinction. Horgan et al. (Horgan, Tienson, \& Graham, 2004; Horgan \& Tienson 2002) take this option when considering a twin earth case of singular thought about George Bush: the twins would have the same narrow intentionality (involving phenomenology), but different 'externalistic' intentionality (involving earth Bush and twin Bush). ${ }^{8}$ Those who take this option may also provide a further story about how the wide features of the mental representations are tied to the narrow. For example, it might be claimed that the narrow phenomenal intentionality, when combined with a particular external context, can uniquely determine which object features as the wide content of the representation: the narrow George Bush-y phenomenology, plus a context that involves the actual (rather than the twin) Bush, will determine that the wide content features George Bush himself; the same narrow phenomenal intentionality on twin earth would determine that the wide content features twin Bush. Mutatis mutandis for the brother and stranger cases.

Another way of making an exclusion is to claim (as above) that the crucial representations in the brother and stranger cases differ with respect to some wide feature, but that this feature is, despite appearances, not intentional. Call this option the intentional exclusion. On this view, what is different between

6. Montague (2016) provides a sketch of what such an account might look like. As Montague points out, Martin distinguishes between 'phenomenal nature' and 'phenomenal character', and in fact wants to say that the phenomenal nature, rather than the phenomenal character, would change across the relevant cases. But without a more detailed story about phenomenal nature it seems such an account would be pushed to say that phenomenal character changes across the relevant cases. For more on this move, see Montague (2016).

7. See Farkas (2008), Horgan \& Tienson (2002), Kriegel (2008a; 2008b), and Strawson (2005).

8. See also Chalmers (2002; 2010). 
the brother and stranger cases is which object is successfully picked out, or referred to, but this difference is not an intentional difference. As Farkas (2008: 274) puts it, 'if one is convinced that narrow phenomenal intentionality is legitimate, there is nothing stopping one from claiming that all intentionality is narrow'. Phenomenal intentionality is narrow, and this kind of intentionality is the only real intentionality (Strawson 2008). Kriegel (2007: 336-337, fn. 54) suggests this sort of move in response to a puzzle analogous to the hooded man puzzle: the outside world changes between cases, but the intentionality remains the same. As with the phenomenal exclusion, there may be a similar story about how the phenomenal intentionality determines this non-intentional reference or 'picking out' of an object. But importantly, this wide feature is not really an intentional feature after all.

\subsection{Evaluating the Options}

While the familiar puzzle is not our main focus, a review of the standard answers to it will be helpful when considering potential responses to our new puzzle.

There is something to be said for holding true. It preserves a central role for phenomenology in giving rise to intentionality quite generally. But this dignity comes at a price. It is prima facie implausible that there is a phenomenal difference between your representations in the stranger and brother cases. You are, to put it crudely, the same from the skin in in the two cases. This idea is supported by the observation that so few defenders of PITs are tempted by this option. Phenomenology seems to be one thing that is common across the cases.

For those who make the intentional exclusion, phenomenology still plays a unique role in determining intentionality, but the scope of intentionality is more restricted than might have been imagined. Theories of intentionality were meant to account for how we think about the world. The brother and stranger cases prima facie involve representations about two different things. This appearance would need to be resisted by those who take this option.

The phenomenal exclusion is a popular option, though some might see reasons for wanting to avoid it. Phenomenal intentionality theories were presented as giving an important and unique role for phenomenology in explaining intentionality. A proper recognition of the phenomenal aspects of intentionality was meant to show that the standard 'naturalistic' accounts of intentionality are deeply unsatisfactory. Mendelovici (2018: 83), for example, states that 'unlike tracking theories and functional role theories, PIT provides the right kinds of ingredients to account for intentionality and is not clearly empirically inadequate'. Strawson (2008: 281) similarly claims that intentionality is an . . essentially experiential (conscious) phenomenon. Any attempt to characterize intentionality that detaches it from conscious experience faces . . . insuperable problems.' 
But for those who take the phenomenal exclusion option, much of the intentional work (indeed the intentional work that naturalistic theories are supposed to handle well) is offloaded to more familiar non-phenomenological resources. To be sure, the narrow phenomenal features still play a key role, when combined with the external context, in uniquely determining the wide intentional features of mental representations, but the resulting role of phenomenology is at least slightly more limited than is sometimes suggested.

So far, so familiar. This is well-trodden ground, and PIT proponents are generally content with one of the established options. In particular, the exclusions remain popular views. After all, (principled) exclusions of this kind can be useful theoretical moves, and modesty of explanatory aims is often a virtue rather than a vice. The focus on narrow content, for example, was explicitly championed by many original PITs as an advantageous feature of the account, on the basis of the psychological import of narrow content (Horgan \& Tienson 2002; Horgan, Tienson, \& Graham 2004; Kriegel 2003; 2008a; Loar 1987). In sum, phenomenal intentionality theorists remain unfazed by challenges of the sort brought out by the hooded man puzzle.

We are sympathetic to some of these lines of reasoning. We are certainly not externalists, and we share a respect for the importance of the narrow features of mental representations. We will now present a new kind of puzzle that raises its own challenges for defenders of PITs. We will argue that the new puzzle exposes the old puzzle as somewhat myopic, in focusing the attention on concrete objects, and that the new puzzle is not so easily handled.

\section{A New Puzzle}

\subsection{Intentional Identity}

Pairs of intentional attitudes are sometimes about the same thing. My judgment that New York is sublime and my co-author's judgment that New York is mundane are about the same thing, New York. They are so, notice, even though we disagree on some features of the thing we are thinking about. We can ask whether any two pairs of representations are about the same thing, but this question is harder and more interesting when we ask it of pairs of representations that seem to be about things that do not exist, such as beliefs about Vulcan (the supposed planet responsible for certain perturbations in Mercury's orbit).

Following Geach (1967), we will say that there is intentional identity when there are two representations that have a common intentional focus (are about the same thing), whether or not there is any object at that intentional focus (an object such that they are both about it). For example, suppose two friends, Jack 
and Jill, live in the same village and read the same newspaper article reporting that a witch has been terrorizing their village. Jack makes the judgment that the witch has been blighting the local mares; Jill makes the judgment that the witch has been killing the local sows. Jack's judgment and Jill's judgment are, it seems, co-intentional, they are about the same thing (even though there is no concrete particular thing such that they are about it). This feature of the case appears to be an intentional feature, and yet it does not obviously depend on the phenomenal features of the case.

As with the hooded man puzzle, there is some pressure on proponents of PITs to explain what is going on when there is co-intentionality. And as with the previous puzzle, there are similar options available. PITs must either show that the puzzle can be explained in terms of phenomenal intentionality (either directly or derivatively) or argue that the puzzling feature is not in fact an intentional one after all.

It is worth noting at the outset what we think makes intentional identity cases interesting, and why we think it is important for PITs to account for the phenomenon. The problem as we see it is that of dealing with empty cases in such a way that one can still answer questions of identity. Empty cases and cases involving the identity of intentional objects have typically been tackled separately by PITs. Questions about the identity and distinctness of intentional objects have typically been considered in concrete object-involving cases, where standard answers involve a key role for the concrete objects the representations are aboutthe common idea is that two thoughts can be about the same thing because they connect up causally with the same concrete thing in the world (e.g., see Farkas 2008; Horgan, Tienson, \& Graham 2004; Horgan \& Tienson 2002; and Strawson 2008). Questions of empty names, on the other hand, have typically been posed as an independent puzzle, answers to which typically invoke a kind of adverbialism, or an internalist (and phenomenalist) sense of notional worlds and notional (rather than relational) aboutness - the ways a person takes the world to be, even if the world in fact is not that way (e.g., see Kriegel 2007; 2008b).

Putting these questions together exposes a key weakness. In empty cases, there are no concrete objects to help secure identity, and the standard notional (phenomenal) approaches to empty names look like they fail to secure identity in any interesting way-these approaches allow us at most to say that if there were an object that satisfies some description, then there would be intentional identity. But what cries out for explanation is when and why there is intentional identity, not when and why there would be intentional identity. Intentional identity seems to be a commonplace intentional phenomenon, as much in empty cases as in non-empty cases. For example, it is an important part of the history of science that many debates involved disagreement about the same thing, where that thing turned out not to exist: Vulcan, phlogiston, and so on. Everyday thought 
and discussion also regularly involves targeting of the same thing where no concrete thing exists: debates about various gods (at least some of which surely do not exist), shared hallucinations, fictional characters, and many others (Azzouni 2010). PITs, as we have seen, have a story about how concrete things are tracked, but it seems like one can track things even when there is no concrete thing being tracked. Co-intentionality of this sort looks like an important intentional phenomenon, though it looks more difficult to explain (or explain away) than the phenomenon described in the familiar puzzle. With this in mind, we turn now to explore the prospects for explaining intentional identity in line with PITs.

\subsection{Holding True Options}

Those who want to hold true with respect to the hooded man puzzle might be tempted to adopt the same strategy here: intentional identity is an intentional phenomenon and is explained in terms of the phenomenal features of the relevant representations. The objects the respective representations were about played an important role in the holding true story with respect to the hooded man puzzle; perhaps they play an analogous role here.

One place to look is to what we might call 'exotic objects' - Platonic witches, non-existent planets, and the like. Maybe what unites the two judgments in the witch case is some abstract, merely possible, or non-existent object that both judgments are about, and the phenomenology (and thus intentionality) in these cases is determined by some exotic object. Indeed, according to some accounts in the literature on this topic (Parsons 1974; Priest 2005; Salmon 2002), intentional identity is a matter of there being an object (exotic or not) that the relevant representations are about. That would seem to fit nicely with the holding true response to the hooded man puzzle.

There are significant problems with this move. Firstly, it is somewhat out of step with the spirit of PITs. Phenomenal intentional theories generally do not draw on these kinds of exotic objects to do explanatory work, and in so far as exotic objects are discussed at all, the prevailing view is that defenders of PITs need not (and should not) countenance them. According to Kriegel (2007; 2008b), for example, intentional states that seem to be directed at, say, a dragon, would be better described in a way that avoids commitment to an exotic object: you judged dragonishly (rather than having a judgment about a dragon). This characterization avoids commitment to merely intentional objects, a commitment associated with 'familiar and truly outstanding liabilities-ontological, epistemological, and phenomenological' (Kriegel 2008b: 83; see also Mendelovici 2018).

What is more, accounts according to which intentional identity is explained (in cases in which the representations are empty) by the presence of some exotic object that both representations are about face a unique challenge, recently em- 
phasized by Sandgren (2018). 9 Sandgren's challenge is based on the observation that the collection of exotic objects often has an uncomfortably large cardinality. Sandgren argues that this fact, combined with the fact that many of the resources to which we usually appeal when assigning objects to representations (e.g., causal connections to the object or eligibility constraints) are unavailable in empty cases, means that one cannot provide an explanation of intentional identity that allows the presence of exotic objects to do the required explanatory work. If the appeal to exotic objects in this context is to be vindicated, this challenge should be met.

If the objects the representations are about do not do the work in explaining intentional identity, another option is to claim that intentional identity or distinctness is determined solely by the phenomenal features of the relevant representations. The idea behind this move is that intentional identity is a matter of the representations having the right sort of phenomenological features in common.

But which phenomenal features are representations required to have in common if they are to be co-intentional? One apparently attractive answer is 'all of them'.$^{10}$ But this answer is unsatisfactory. Agents can disagree about the witch. For example, Jack might judge the witch to be evil, while Jill might judge her to be well-intentioned but misguided. This disagreement will be reflected in the way the witch is presented to them, and thus, ex hypothesi, will be reflected in the phenomenology of the respective representations. If exact sameness of phenomenology were required for intentional identity, disagreements of this sort would be impossible.

One might be tempted to instead claim that intentional identity is a matter of the relevant representations having some, but not necessarily all, their phenomenal features in common. That is, one might claim that intentional identity occurs when representations are phenomenally similar. According to Geach (1967), intentional identity is a matter of the representations sharing the same aspect, where aspects are close cousins of Fregean senses. The defender of PITs could adopt an analogous view according to which aspects are individuated phenomenologically. According to this view, again in line with Geach's proposal, witch-aspects need not be aspects of a witch, so this proposal does not require us to appeal to exotic objects. The idea is, roughly, that what makes for intentional identity is similarity of phenomenology - that is, there is some crucial element of the respective representations' phenomenology that means that they are about the same thing.

9. Note that Sandgren is not arguing that there are no exotic objects; rather, he is arguing that even if there are, they cannot do the required explanatory work.

10. Mendelovici gestures at this sort of view (2018: 211-212), though she admits (2018: 212, fn. 28) that intentional identity might sometimes depend on mere partial overlap of phenomenal features (a proposal we consider below). 
Here is an argument that this sort of move is unattractive. Consider variants of the brother and stranger cases in which you also make a judgment concerning your brother's table tennis skills (formed on the basis of a perceptual experience of him playing table tennis). In both cases, your judgment concerning your brother's table tennis skills is uncontroversially about your brother. So let us now consider the question, is your judgment concerning your brother's table tennis skills about the same thing as your judgment about the man drinking at the bar? The answer seems to be yes in the brother case and no in the stranger case. If intentional identity is a matter of phenomenal similarity, then the judgment about the man at the bar must be phenomenally similar to the table tennis judgment in the brother case but not in the stranger case. But since similarity is symmetric, the only way this could be true is if there is a phenomenal difference between the judgments concerning the man at the bar in the brother and stranger cases. But these judgments appear to have the very same phenomenology, so something has gone wrong. The PIT theorist who holds true in this way is forced to claim that there is yet another phenomenal difference between the judgments made in the brother and stranger cases, beyond any difference purportedly tied to the difference in which object is sitting at the bar, when there appears to be none.

The phenomenal similarity account faces yet another challenge. Edelberg (1992) argues convincingly that intentional identity exhibits a certain feature that seems difficult to capture given a simple similarity theory like the one in hand. ${ }^{11}$ Imagine a variation on the Jack and Jill case. A newspaper reports that a witch has been terrorizing the village. Jack makes the judgment that the witch has been blighting the local mares; Jill makes the judgment that the witch has been killing the local sows. So far this is just the original example, and Jack and Jill's judgments are about the same thing. But Jack and Jill now go and examine what they take to be evidence and come to the following judgments: Jack and Jill think one witch blighted the mares, but Jill thinks the sows' fate was the work of a second witch whereas Jack thinks one witch blighted the mares and killed the sows. Now suppose we ask, is Jack's judgment concerning the witch that blighted the mares about the same thing as Jill's judgment about the witch that killed the sows? The answer appears to be 'yes in one sense and no in another'. If we consider Jill's views on the matter, we are tempted to say they are not about the same thing - after all, Jill thinks that the two acts of livestock maligning were committed by distinct witches. But if Jack's views are made salient, we are tempted to say they are about the same thing-Jack thinks there is just one witch responsible for the two attacks. So it seems as if, in some way or other, intentional identity reflects the difference between Jack and Jill's respective views about how things are. But if phenomenal similarity is what makes for intentional

11. For a recent summary of this challenge see Section 6 of Sandgren (in press). 
identity, it is difficult to see how we are to capture this fact. Either the judgments will be similar in the required way or they will not. There is no room, it seems, for the different views of Jack and Jill to make the required difference to the facts about intentional identity. ${ }^{12}$

Perhaps this challenge could be met by a more complicated account of the relevant dimensions of phenomenal similarity. Perhaps which dimensions of similarity matter for intentional identity shifts from context to context and this is how we ought to capture the sensitivity to Jack and Jill's different perspectives. ${ }^{13}$ We will leave it to defenders of PITs to develop this or alternative responses to the challenge these Edelberg-style cases pose. At any rate, it is clear that more work is needed and more refinements are required to allow defenders of PITs to hold true in the face of this challenge.

Those who claim that intentional identity is a matter of phenomenal similarity hold true in that they allow the phenomenal features of representations a crucial place in the explanation of intentional identity. In this respect the move should be attractive. But as we have seen, the resulting view of intentional identity faces significant challenges.

More generally, flat-footedly appealing to 'phenomenal similarity' is really just a gesture in the direction of a satisfactory account of intentional identity. There are always, between any two representations that have phenomenal features, a myriad of phenomenal differences and similarities. If the appeal to phenomenal similarity is to be anything more than a gesture or promissory note, we are owed an account of which kinds of phenomenal similarity make for intentional identity. Perhaps an account of this sort could be developed, and in a way that also provides an answer to the challenges outlined above, but such an account remains to be articulated.

\subsection{Exclusion Options}

Those who opted for an intentional exclusion as regards the hooded man puzzle denied that the brother and stranger cases were intentionally different, instead claiming that it was simply a (non-intentional) difference in objects (or reference to the objects). Those attracted to this stance might want to make a similar move here, offloading the work onto other resources, and denying that the phenomenon is really intentional (despite appearances).

12. Note intentional identity is still objective, in some sense-they can be ignorant or mistaken about which representations their attitudes are about the same thing as. The attitudes might be about the same thing though they believe they are not, they might not be about the same thing though they believe they are, and they might be about the same thing without the relevant agents realising that fact.

13. Glick (2012) and Sandgren (in press) defend views of intentional identity that are shifty in this way, though neither claim that what shifts is which kind of phenomenal similarity is in play. 
There are problems with this move. For reasons discussed above, the obvious choice of resource for those who make this move-objects-is not available in the empty case. It appears unattractive to turn to exotic objects in an attempt to offload the explanatory work.

Even if this worry could be overcome, and the intentional work could be offloaded onto some resource other than objects, it would be a strange move for PITs to deny that intentional identity is an intentional phenomenon. For one thing, intentional identity in empty cases looks like the kind of thing PITs should be well-equipped to deal with. Phenomenal intentionality theories primarily focus on the way the object is presented, rather than the object itself. Non-empty cases, such as the familiar hooded man cases, pose a challenge for PITs precisely because they seem to involve a non-presentational element, in the form of the actual external object. But in empty cases, the only obvious resources that are available to explain co-intentionality are the facts about how the purported target is represented, which are exactly the resources defenders of PITs tend to rely on in their discussion of intentionality. This is at least a prima facie reason to suppose that intentional identity is the kind of thing PITs should be able to explain. It is also a prima facie reason to suppose that intentional identity is the kind of thing PITs should accept as intentional-unlike the concrete object cases, intentional identity in empty cases seems to involve only modes of presentation, the very stuff of phenomenal intentionality.

Finally, there are reasons to worry about making the intentional exclusion as regards both the hooded man cases and cases of intentional identity. For now there are two seemingly intentional phenomena that the theory classifies as nonintentional after all. Moreover, one of those phenomena - intentional identityappears to involve the kinds of modes of presentation that PITs typically focus on. While it is of course reasonable that a theory of intentionality might suggest adjustments in what should count as intentional, when a theory starts to exclude too many phenomena that are typically counted as intentional, this is at least a reason to worry, especially in the absence of some principled reason for these revisions. In the hooded man puzzle, we agree that there might be a principled reason for being moved to exclude the wide features as being intentional-the internalist response, after all, is an old move in an old battle; far be it from us to stir up the dust after it has settled. But the case is different in the current puzzle. Claiming that intentional identity is not an intentional phenomenon involves giving up an awful lot of (intentional) ground.

Those who adopted the phenomenal exclusion option in response to the familiar puzzle, on the other hand, might be tempted to make a similar move in response to the new puzzle. The idea is to accept that intentional identity is indeed intentional, but deny that it is best captured in phenomenological terms.

This move has the result that phenomenal intentionality views now look far 
less phenomenal. Those who continue to appeal to the phenomenal exclusion option in the face of the intentional identity puzzle seem to be pulling something like a bait and switch. PITs were supposed to help us explain how mental states and representations glom onto the world. This is indeed what phenomenal intentionality theorists promise when specifying their explanatory ambitions. In a recent treatment of phenomenal intentionality, Montague (2016: 7) states that intentionality 'is nothing more or less than the phenomenon of something's being about something or of something in the sense of "of" given which a picture can be said to be of something, such as a bath or a battle.' Another recent treatment of phenomenal intentionality begins:

some mental states seem to be "of" or "about" things, or to "say" something. For example, a thought might represent that grass is green, and a visual experience might represent a blue cup. This is intentionality. The aim of this book is to explain this phenomenon. (Mendelovici 2018: abstract)

The defenders of PITs seem to agree that a theory of the intentionality of mental states is supposed to tell us how mental states can be about baths and battles (brothers and witches). But what differs in the brother and stranger cases is which person your representation is about, and what makes for intentional identity in the cases we described is which witch the relevant representations are about. $^{14}$ Those who take the phenomenal exclusion option leave no major role for phenomenology in accounting for this kind of intentionality ${ }^{15}$ (a particularly surprising result in the case of intentional identity in empty cases, given that, as we have suggested, the phenomenon is ostensibly well suited to the typical scope of PITs). The promise was that phenomenal intentionality theories would help explain how we could represent objects in the world by appealing to phenomenal features of representations. Those who take the phenomenal exclusion option in the face of both the reviewed puzzles fail to deliver what was promised.

Of course, it is open to the proponent of PITs to insist that while intentional

14. Note that one does not have to be an externalist to accept this. As Stalnaker (1999: 170) says, something like this must be accepted by 'any account of representation that holds that we can talk and think, not just about our own inner states, but also about things and properties outside of ourselves'. This is in fact also accepted by many proponents of PITs. Horgan and Tiensen (2002: 528), for example, when considering a twin earth case of singular thought about Bill Clinton, say, 'Your own thoughts are about the actual Bill Clinton. Your Twin Earth doppelganger's thoughts are about a different person on Twin Earth.'

15. Those who take the intentional exclusion deny that it is a kind of intentionality at all, which we think is a different kind of bait and switch: we were promised an explanation of how we think about baths and battles (brothers and witches), but then the intentional exclusion backs down, implying that these phenomena are not even intentional at all. 
identity is not directly a case of phenomenal intentionality, the phenomenology still has a unique role in determining, within some given context, which witch the representations are about. Such a response would be analogous to the phenomenal exclusion claim made regarding the hooded man puzzle, wherein the wide features were able to be derived from the narrow together with a particular context.

But in contrast to the hooded man case involving concrete objects, we cannot see how phenomenology can do the job here. Take, for example, Farkas's (2008) proposal regarding names and descriptions. Farkas argues for a distinct kind of 'name phenomenology' and 'description phenomenology', wherein these different types of phenomenology specify the external satisfaction conditions of thoughts involving names and descriptions. These conditions, in a particular context, would then determine which object is picked out. Perhaps there could be a kind of 'empty name phenomenology' wherein the satisfaction conditions are similarly spelled out so as to account for the intentional identity in the witch case.

This is an interesting idea, though there are prima facie obstacles. Firstly, are we to take it that empty name phenomenology is a distinct type of phenomenology, in addition to name and description phenomenology? That would seem to be required, since empty cases do not appear to involve the same kinds of satisfaction conditions as non-empty cases-Farkas lists name phenomenology as pointing to causal history, but it is plausible that no such causal chain is required in empty cases (Sandgren in press: 7-8). But then it is not clear that such a distinct phenomenology could be present in addition to non-empty name phenomenology. For consider, one can be unaware that one is using an empty name. The fact that a name is empty does not seem to be reflected in its phenomenology; if it was, we would expect users of the name to be immediately aware that it is empty just on that basis, but that seems false. In that case, which satisfaction conditions are given in the phenomenology, those for names or those for empty names? The challenge here is not just to specify what the conditions are for determining intentional identity, in addition to explaining the phenomenology such that it fixes those conditions, but to show how this new kind of case can fit into existing proposals that deal with the hooded man puzzle.

To be sure, nothing we have said here rules out the possibility that phenomenology can do the job. But we need to be shown just how it can be done. Perhaps some other proposal for deriving the intentional identity from the phenomenology (within a given context) can be made to work. We again leave it open to the PIT proponent to provide such an account. 


\subsection{Mixing Options}

We have so far considered options for addressing the new puzzle that align with the standard options for responding to the familiar puzzle. Presenting the puzzles in this way provided a useful framing, suggesting possible responses to the new puzzle. But one might respond to the two puzzles in different ways. Indeed, there might be distinctive advantages associated with doing so.

For instance, one could take the intentional exclusion option in response to the familiar puzzle but then hold true with respect to the new puzzle. That might have the advantage of adopting an established response to the familiar puzzle while avoiding the costs associated with the intentional exclusion option when applied to both cases. Or one could take the intentional exclusion option as regards the new puzzle but not the familiar puzzle, under the assumption that the new puzzle involves a less central case of intentionality. If you think that empty cases are less paradigmatically intentional than non-empty cases, you might find it less costly to take the intentional exclusion solely in response to the new puzzle.

A mixed strategy may thus avoid some of the problems we signaled above. Taking similar exclusion options in response to both puzzles may incur some extra costs distinct from the costs associated with the exclusion moves taken separately, and that is something that can be avoided by mixing options.

However, an answer is still required to the criticisms that do not hinge on adopting similar options in response to both puzzles. For example, a defender of the phenomenal exclusion will need to say why phenomenology does not do the explanatory work in a case that seems so well-suited to the typical explanatory scope and strategy of phenomenal intentionality theories.

Additionally, while there may be unique advantages to taking a mixed set of options, there may well be unique disadvantages. One might think that each of the puzzles is importantly concerned with identifying and differentiating what representations are about. Inasmuch as one thinks that, one may have a reasonable (though defeasible) preference for a unified explanation of that phenomenon. ${ }^{16}$ Of course, there are differences between the cases-one involves empty representations, the other does not-but the defender of a mixed strategy should say why these differences make a difference.

Note that we may simply have been insufficiently creative in formulating

16. Note that this is true even though, as it stands, only the first puzzle is presented as a direct violation of the supervenience claim of PITs. Both puzzles concern intentional identification, and it is reasonable to suppose they might require similar answers. The new puzzle might also be able to be framed as an apparent violation of supervenience (though we did not frame it in this way), since an explanation of intentional identity can have implications for when there are intentional differences between cases. 
potential responses, and a creative defender of PIT might formulate a novel kind of response to the new puzzle (and perhaps to the familiar puzzle as well). We leave this as an open possibility. We hope that this work will facilitate the search for such a response, by flagging potential pitfalls and highlighting more promising avenues.

\subsection{Taking Stock}

We have suggested that intentional identity poses a challenge for PITs, and though we left open the possibility of providing a satisfactory answer to the puzzle, we do not see any obvious resources for doing so.

A few things are worth noting. Firstly, note that this puzzle is indeed a new one for PITs. There are four standard challenges to PITs (Bourget \& Mendelovici 2017): the issue of wide intentionality; the phenomenal intentionality of thought; the intentionality of standing states; and the intentionality of occurrent unconscious states. In the course of our discussion we reviewed some possible answers to the issue of wide intentionality (as seen in the hooded man puzzle). We also implicitly granted, for the sake of argument, that there could be some kind of phenomenal intentionality involving thought. Finally, in framing all our examples in terms of conscious occurrent states we elided over the challenges involving the intentionality of standing states (e.g., beliefs), as well as occurrentbut-unconscious states. We are thus working under the supposition that there are good answers to the extant challenges discussed in the literature. By granting all this and still being in a position to pose a puzzle based on intentional identity, we aimed to show that whether or not one takes the familiar challenges to be surmountable, another puzzle remains.

It is also worth addressing a concern the reader might have. The reader might object that intentional identity is so puzzling in the first place that it is unfair to criticize PITs for not having a good account of it. Successful accounts of intentional identity are so rare that intentional identity is, in a sense, a problem for everyone.

The first thing to note is that a problem for everyone is not a problem for no one, despite the temptation some feel to make this claim while fending off objections (Nolan \& Sandgren 2014: 621-622). Intentional identity is a puzzling phenomenon that demands an explanation, and it is worth considering the prospects of explaining it in line with various views of intentionality like PITs.

Further, there are reasons to think it is not everyone's problem. There has recently been a modest but progressing debate about intentional identity and how to make sense of it. For example, we think the work of Perry (2001), Salmon (2002), Priest (2005), Sainsbury (2010), Glick (2012), Friend (2014), Pagin (2014), and Sandgren (in press) makes good ground in the project of explaining inten- 
tional identity. This isn't to say that the debate about intentional identity is over, but that these accounts have developed some strategies for dealing with some of the intricacies concerning intentional identity that we have discussed. For example, the causal chains between representations in cases like the Jack and Jill case are generally agreed to be central to the explanation of intentional identity in those cases.

Moreover, our discussion has suggested that there is a unique challenge for PITs in dealing with intentional identity, in that it is not obvious that it has the resources to do so. Crucially, extant theories of intentional identity tend not to appeal to phenomenal explanatory resources. Since the central claim of PITs is that phenomenology plays a crucial role in giving rise to intentional features of representations (which appears to include intentional identity facts), PITs face a distinctive challenge regarding intentional identity. They must either explain how phenomenal resources are central to explaining intentional identity, or they must limit, in one way or another, the explanatory ambitions of PITs.

One final note regarding explanatory ambitions. Just as with the exclusions as regards the hooded man puzzle, we take it that some will no doubt be willing to pay the price-it just turns out the role of phenomenology (or intentionality) is more restricted than has sometimes been supposed.

So be it. But those who take this option ought to be clearer about the explanatory ambitions of PITs. If you think intentionality, properly speaking, does not extend to cases like those we have described, be clear about exactly what your version of PIT is supposed to explain, and what its limitations are. Similarly, if you think that the phenomena we have described are intentional, but not phenomenal, tell us why the phenomenology does not do the work in these cases, and how precisely they differ from the cases where phenomenology does do the intentional work. From there, we can make informed choices about what to buy into and where the price is too steep.

\section{Conclusion}

We have posed a puzzle for phenomenal intentionality: how to handle intentional identity given the commitments of PIT. Though the puzzle raises interesting issues in its own right, it has been illuminating to consider how the problem might be solved in line with the standard answers to a more familiar puzzle.

The holding true option comes out looking somewhat attractive. It yields a distinctive role for phenomenology in explaining intentional identity. Additionally, we left open the possibility that phenomenal similarity between representations might do the work, though an account of this sort would still need to be developed and defended before the challenge we have raised can be considered met. 
Of the exclusion options, the phenomenal exclusion perhaps remains the most attractive when considered in light of the new puzzle. Those who take this option can maintain the standard view that both puzzles involve intentional phenomena. Of course, in doing so they limit the phenomenal scope of phenomenal intentionality theories. But perhaps that is as it should be.

The intentional exclusion appears to be in more serious trouble. The intentional exclusion, in relation to the familiar object-involving cases, might appear attractive, in that it maintains a strong stance on the importance of phenomenology in all intentionality. But the puzzle based on intentional identity shows that there may be a greater range of prima facie intentional phenomena that this view simply does not attempt to explain. In that case, the view only explains all intentionality inasmuch as the category of intentional phenomena is more limited than one might have supposed.

We see no clear way forward for phenomenal intentional theories. This might be taken as a challenge to PITs: either give an account of intentional identity that applies uniquely phenomenological resources or clarify the explanatory ambitions of the view. We pose this challenge in the hopes that perhaps some may hold true, and show how phenomenal intentionality can remain novel and interesting, while explaining a wide range of intentional phenomena.

\section{Acknowledgements}

We would like to thank members of two work-in-progress groups at ANU, the Mind group and Colin's Crowd, including Maeva Bennotto-Peris, Justin D'ambrosio, Frank Jackson, Colin Klein, Don Nordblum, Ross Pain, and Daniel Stoljar. Further thanks are due to Renée Jorgensen Bolinger, Bronwyn Finnigan, Stephen Gadsby, Erick Llamas, and Michelle Liu, for their feedback and discussion. Finally, we are grateful to three anonymous reviewers for their helpful comments. This research was supported by an Australian Government RTP scholarship (P.C).

\section{References}

Azzouni, Jody (2010). Talking about Nothing: Numbers, Hallucinations, and Fictions. Oxford University Press.

Bailey, Andrew and Bradley Richards (2014). Horgan and Tienson on Phenomenology and Intentionality. Philosophical Studies, 167(2), 313-326.

Bordini, Davide (2017). Is There Introspective Evidence for Phenomenal Intentionality? Philosophical Studies, 174(5), 1105-1126.

Bourget, David and Angela Mendelovici (2017). Phenomenal Intentionality. In Edward 
N. Zalta (Ed.), The Stanford Encyclopedia of Philosophy (Spring 2017 ed.). Retrieved from https://plato.stanford.edu/entries/phenomenal-intentionality/

Chalmers, David J. (2002). The Components of Content. In David J. Chalmers (Ed.), Philosophy of Mind: Classical and Contemporary Readings (6o8-633). Oxford University Press.

Chalmers, David J. (2010). The Character of Consciousness. Oxford University Press.

Edelberg, Walter (1992). Intentional Identity and the Attitudes. Linguistics and Philosophy, $15(6), 561-596$.

Evans, Gareth (1982). The Varieties of Reference. Oxford University Press.

Farkas, Katalin (2008). Phenomenal Intentionality without Compromise. The Monist, 91(2), 273-293.

Forrest, Peter V. (2017). Can Phenomenology Determine the Content of Thought? Philosophical Studies, 174(2), 403-424. https://doi.org/10.1007/s11098-016-0689-0

Friend, Stacie (2014). Notions of Nothing. In Manuel Garcia-Carpintero and Genoveva Marti (Eds.), Empty Representations: Reference and Non-Existence (307-332). Oxford University Press.

Geach, Peter T. (1967). Intentional Identity. Journal of Philosophy, 64(20), 627-632.

Glick, Ephraim (2012). A Modal Approach to Intentional Identity. Noûs, 46(3), 386-399.

Goff, Philip. (2017). Conscious Thought and the Cognitive Fine-Tuning Problem. The Philosophical Quarterly, 68(270), 98-122.

Horgan, Terence (2013). Original Intentionality is Phenomenal Intentionality. The Monist, 96(2), 232-251.

Horgan, Terence and John Tienson (2002). The Intentionality of Phenomenology and the Phenomenology of Intentionality. In David J. Chalmers (Ed.) Philosophy of Mind: Classical and Contemporary Readings, (520-533). Oxford University Press.

Horgan, Terence, John Tienson, and George Graham (2004). Phenomenal Intentionality and the Brain in a Vat. In Richard Schantz (Ed.), The Externalist Challenge (297-317). Walter de Gruyter.

Kriegel, Uriah (2003). Is Intentionality Dependent upon Consciousness? Philosophical Studies, 116(3), 271-307.

Kriegel, Uriah (2007). Intentional Inexistence and Phenomenal Intentionality. Philosophical Perspectives, 21(1), 307-340.

Kriegel, Uriah (2008a). Real Narrow Content. Mind \& Language, 23(3), 304-328.

Kriegel, Uriah (2008b). The Dispensability of (Merely) Intentional Objects. Philosophical Studies, 141(1), 79-95.

Kriegel, Uriah (2011). Cognitive Phenomenology as the Basis of Unconscious Content. In Tim Bayne and Michelle Montague (Eds.), Cognitive Phenomenology (79-102). Oxford University Press.

Kriegel, Uriah (Ed.) (2013). Phenomenal Intentionality. Oxford University Press.

Loar, Brian (1987). Subjective Intentionality. Philosophical Topics, 15(1), 89-124.

Martin, Mel G. F. (2002a). Particular Thoughts \& Singular Thought. Royal Institute of Philosophy Supplements, 51, 173-214.

Martin, Mel G. F. (2002b). The Transparency of Experience. Mind \& Language, 17(4), 376425 .

McDowell, John (1986). Singular Thought and the Extent of 'Inner Space'. In John McDowell, Philip Pettit (Eds.), Subject, Thought, and Context (137-168). Oxford University Press. 
Mendelovici, Angela (2018). The Phenomenal Basis of Intentionality. Oxford University Press.

Mendelovici, Angela and David Bourget (2014). Naturalizing Intentionality: Tracking Theories versus Phenomenal Intentionality Theories. Philosophy Compass, 9(5), 325337 .

Montague, Michelle (2016). The Given: Experience and its Content. Oxford University Press.

Nolan, Daniel and Alexander Sandgren (2014). Creationism and Cardinality. Analysis, $74(4), 615-622$.

Pagin, Peter (2014). Intersubjective Intentional Identity. In Manuel Garcia-Carpintero and Genoveva Marti (Eds.) Empty Representations: Reference and Non-Existence (91113). Oxford University Press.

Parsons, Terence (1974). A Prolegomenon to Meinongian Semantics. The Journal of Philosophy, 71(16), 561-580.

Perry, John (2001). Reference and Reflexivity. Center for the Study of Language and Information.

Priest, Graham (2002). The Hooded Man. Journal of Philosophical Logic, 31(5), 445-467.

Priest, Graham (2005). Towards Non-Being: The Logic and Metaphysics of Intentionality. Oxford University Press.

Sainsbury, R. Mark (2010). Intentionality without Exotica. In Robin Jeshion (Ed.), New Essays on Singular Thought (300-318). Oxford University Press.

Salmon, Nathan (2002). Mythical Objects. In Joseph K. Campbell, Michael O'Rourke, and David Shier (Eds.), Meaning and Truth: Investigations in Philosophical Semantics (105123). Seven Bridges Press.

Sandgren, Alexander (2018). Which Witch is Which? Exotic Objects and Intentional Identity. Synthese, 195(2), 721-739.

Sandgren, Alexander (in press). A Metarepresentational Theory of Intentional Identity. Synthese.

Searle, John R. (1992). The Rediscovery of the Mind. The MIT Press.

Stalnaker, Robert C. (1999). Context and Content: Essays on Intentionality in Speech and Thought. Oxford University Press.

Strawson, Galen (2005). Intentionality and Experience: Terminological Preliminaries. In David W. Smith, and Amie L. Thomasson (Eds.) Phenomenology and Philosophy of Mind (41-66). Oxford University Press.

Strawson, Galen (2008). Real Intentionality 3: Why Intentionality Entails Consciousness. In Real Materialism and Other Essays (281-306). Oxford University Press.

Strawson, Galen (2009). Mental Reality. The MIT Press. 